\title{
"For whom was it effective?" Moderators of the effect of a school-based intervention on potential physical activity determinants among Brazilian students
}

\author{
Valter Cordeiro Barbosa Filho a,b,c,*, Kelly Samara da Silva a ${ }^{\text {a }}$ Jorge Mota ${ }^{c}$, Neiva Francenely Cunha Vieira ${ }^{\text {b,d }}$, \\ Fabiane do Amaral Gubert ${ }^{\mathrm{b}, \mathrm{d}}$, Adair da Silva Lopes ${ }^{\mathrm{a}}$ \\ a Research Centre in Physical Activity and Health, Department of Physical Education, Federal University of Santa Catarina, Florianópolis, Brazil \\ ${ }^{\mathrm{b}}$ Research Centre in Physical Activity and Health in School, Institute of Physical Education and Sports, Federal University of Ceará, Fortaleza, Brazil \\ ${ }^{\mathrm{c}}$ Research Centre in Physical Activity, Health and Leisure, Faculty of Sport, University of Porto, Porto, Portugal \\ ${ }^{\mathrm{d}}$ Aids Project: Education and Prevention, Department of Nursing, Federal University of Ceara, Fortaleza, Brazil
}

\section{A R T I C L E I N F O}

\section{Article history:}

Received 21 July 2016

Received in revised form 9 January 2017

Accepted 17 January 2017

Available online 19 January 2017

\section{Keywords:}

Motor activity

Associated factors

Socioecological theory

Obesity

Socioeconomic factors

Health and environment

Clinical trial

Vulnerable populations

\begin{abstract}
A B S T R A C T
Knowledge about the effects of school-based interventions on modifiable physical activity (PA) determinants (e.g., social support), and whether the intervention effect differs according to students' characteristics (e.g., age and gender) are relevant PA promotion topics. This study aims to answer these topics among Brazilian students. This cluster-randomized controlled trial was conducted with 548 students in the intervention group and 537 in the control group (51.5\% of boys; aged 11-18 years). The four-month intervention included strategies focused on training teachers, opportunities for PA in the school environment, and health education. Potential PA determinants (attitude, self-efficacy, support of friends, parents, and teachers, perceived neighborhood environment and PA facilities in school) and moderators (gender, age, socioeconomic status (SES), and PA level at baseline) were assessed using self-reported instrument. Height and weight were measured to estimate the students' body mass index (BMI) status. Generalized linear models were used. In general, there was a significant and positive intervention effect for attitude, support of friends and teachers for PA, as well as PA facilities in school; effect size was $0.29,0.24,0.34$, and 0.29 , respectively $(P<0.05)$. Age (support of friends, parents and teachers, and PA facilities in school), SES (support of friends and PA facilities in school), and BMI status (support of friends) were moderators of the intervention effect on some outcomes. In conclusion, the intervention improved potential PA determinants, but some changes occurred differently according to students' characteristics. These findings should be considered in PA policies in the school context.

Trial registration. This study is registered at Clinicaltrials.gov NCT02439827.
\end{abstract}

(c) 2017 Elsevier Inc. All rights reserved.

\section{Introduction}

Promoting physical activity (PA), including at early ages, is a public health priority (World Health Organization (WHO), 2013). However, this priority has become a public health challenge because physical inactivity rates are high (around $80 \%$ of inactive students worldwide) (Hallal et al., 2012) and there is limited evidence of the effectiveness of PA-promoting interventions among young people, especially in low- and middle-income countries (Langford et al., 2014; Demetriou and Höner, 2012).

\footnotetext{
* Corresponding author at: Universidade Federal de Santa Catarina, Centro de Desportos, Departamento de Educação Física, Campus Universitário - Trindade, 88040900, Florianópolis, SC, Brazil.

E-mail address: valtercbf@gmail.com (V.C. Barbosa Filho).
}

Many factors may contribute to PA practice during adolescence. Considering the socio-ecological perspective, modifiable PA determinants from intrapersonal (e.g., self-efficacy), interpersonal (e.g., social support) and environmental (e.g., perceived school environment) levels can affect the choice of a younger individual to be physically active or not (Ferreira et al., 2007; Perry et al., 2012; Sallis et al., 2008). Changing PA behavior is a complex process, and knowledge of the effectiveness of interventions on potential PA determinants can identify important influences that may pave the way for behavior change at a later stage, as well as avoiding the underestimation of important intervention effects (Bergh et al., 2012). Hence, potential PA determinants could be considered endpoints in themselves, (Perry et al., 2012; Brown et al., 2013; Salmon et al., 2009) and multicomponent interventions trend to be more successful in promoting PA whether positive changes occur on potential PA determinants from different levels (Ferreira et al., 2007; Sallis et al., 2008). 
Systematic reviews have shown little or inconsistent evidence of the effect of interventions on potential PA determinants based on a socioecological perspective, especially on interpersonal and environmental PA determinants (Demetriou and Höner, 2012; Perry et al., 2012; Brown et al., 2013; Salmon et al., 2009). Another relevant question is whether a feature of the target audience affects the direction and/or strength (i.e., moderator variable) of the intervention effect on PA determinants (Yildirim et al., 2011). Studies have reported that the practice and preference for PA can be different according to gender, (Perry et al., 2012; Brown et al., 2013; Salmon et al., 2009) age, (Demetriou and Höner, 2012; Cook et al., 2014) socioeconomic status (SES), (Yildirim et al., 2011; Grydeland et al., 2013) PA level, (Grydeland et al., 2013; Taymoori et al., 2008) and body mass index (BMI) status (Bergh et al., 2012; Grydeland et al., 2013). Consequently, these variables can also moderate the effect of an intervention on PA-related variables. However, studies on moderators of the intervention effect on potential PA determinants are rare (Demetriou and Höner, 2012; Bergh et al., 2012; Yildirim et al., 2011).

Answering the question "for whom was it effective?" can help to understand the specific groups of students in which interventions led to substantial changes on PA-related outcomes (Bergh et al., 2012; Yildirim et al., 2011). Expanding this taxonomy is fundamental to research and practice in PA promotion (Gubbels et al., 2014) and can provide knowledge of the need to target subgroups differently when designing and implementing interventions with young people.

We conducted a multicomponent school-based intervention (Fortaleça sua Saúde program) (Barbosa Filho et al., 2015) that was effective in promoting PA practice among Brazilian students (Barbosa Filho et al., 2016a). In this paper, we aimed to evaluate the effect of this intervention on potential PA determinants and whether gender, age, SES, nutritional status, and PA level at baseline were moderators of the intervention effect among students. We hypothesized that the intervention would be effective in improving potential PA determinants from different levels, however some changes could occur differently according to students' characteristics.

\section{Methods}

\subsection{Study design and sample}

This was a cluster-randomized controlled trial (school as a sample selection unit) that was detailed previously, including a flowchart of the study based on the Consolidated Standards of Reporting Trials recommendations (Barbosa Filho et al., 2015; Barbosa Filho et al., 2016a). The participation of the students involved in this study was authorized by the parent/guardian by signing the informed consent. The National Research Ethics System (protocol No. 17366313.9.0000.0121) approved this research project. This study is registered at Clinicaltrials.gov (NCT02439827).

This study was conducted in Fortaleza, in northeast Brazil. In 2014, all six full-time schools of the city that were linked to a national program called School Health Program were included. We performed a random selection of three schools to each condition (intervention or control). All schools were in areas with a low Human Development Index (HDI, a composite index ranging from zero to one - the closer of number one more developed is the neighborhood - based on life expectancy, education level and standard of living): $0.215,0.341$ and 0.443 for the intervention schools, and $0.170,0.377$ and 0.491 for the control schools (Instituto Brasileiro de Geografia e Estatística, 2010).

Eligible participants were 1272 students (639 in intervention and 633 in control schools) who were enrolled in 40 Grade 7 to 9 classes. Of these, 1182 students filled out the baseline measures $(92.0 \%$ and $93.8 \%$ of eligible students from intervention and control schools, respectively) and 1085 completed the follow-up measure (response rate of 93.2\% and $90.4 \%$ in intervention and control schools, respectively) (Barbosa Filho et al., 2015). Dropouts were similar to the participants in all variables, except for age group, where dropouts were significantly older than participants $(P<0.01)$ (Barbosa Filho et al., 2016a).

\subsection{Intervention description}

A detailed description of the intervention can be found in a previous publication, including a description of how the potential PA determinants were focused in intervention strategies (Barbosa Filho et al., 2015). In summary, the intervention was based on different theoretical aspects, including the socio-ecological theory (Sallis et al., 2008) and the concept of the Health Promoting Schools (Langford et al., 2014). The intervention schools had four main component strategies, and control schools had no intervention (Barbosa Filho et al., 2015).

The first component involved training and activities in the general curriculum. All teachers from the three intervention schools were invited to participate in training and to perform lessons in the classrooms that discussed active and healthy lifestyles. A four-hour training session was conducted at the beginning of the school semester regarding the relationship between health, school and academic performance. Teachers received a supplemental manual in order to help with classroom activities. In general, the activities performed in the classroom included text production, production and exposition of videos, posters and/or booklets (newsletters or flyers) on different health issues.

The second component included a four-hour physical education (PE) teacher-specific training conducted at the beginning of the school semester. A supplemental manual with lesson plans and handouts was also developed and distributed to teachers. All PE classes (20 classes with two PE lessons per week) during the semester were supported by an undergraduate PE student. In addition, poster and text material were produced by the students during the classwork or the homework.

The third component included opportunities in the school environment to engage in physical activity. Supervised 10 to 15 min sessions called "Gym in School" were performed twice a week. These sessions were composed of activities in small and large groups in order to involve young people in PA during free-time at school. A staff member conducted these sessions in a variety of open spaces in the school (e.g., courtyard or court). Space and equipment were structured and made available for playing games during free-time in the school day. All games were supplemented by banners displayed in schools that explained the game rules and how to access equipment.

The last component involved health education in the school community. The materials produced in the classroom and PE classes (e.g., posters, newsletters and flyers on health issues) were available in schools. In addition, pamphlets were directed at students and parents. The pamphlets were delivered to a member of the school administration (coordinator or director), and they were delivered early in the school day, during classes, and parent/teacher meetings in school.

\subsection{Variables}

We used a previously validated instrument to measure eight potential PA determinants (see Supplementary Material A) (Barbosa Filho et al., 2016b). The scales of attitude (five items) and self-efficacy (eight items) for PA practice evaluated intrapersonal PA determinants. The scales of interpersonal PA determinants included social support of friends (five items), parents (six items) and the school's teachers (five items) for PA practice. The scales of environmental PA determinants evaluated the youth's perception of neighborhood safety, PA facilities in the neighborhood (five items each) and PA facilities in school (three items).

Potential moderators were measured at baseline using self-reported instruments. SES was represented by the instrument of the Brazilian Association of Research Companies (Associação Brasileira das Empresas de Pesquisa, 2013). This instrument puts subjects into groups economic class groups based on a score combining ownership of assets, parents' schooling and the number of employees in the household. The 
economic classes were grouped into A + B (higher SES) and C + D + E (lower SES) because there was a low sample size in categories $\mathrm{D}$ and $\mathrm{E}$ (125 adolescents). Gender and age groups were reported. A PA instrument validated for Brazilian adolescents was used to estimate the weekly time spent on moderate to vigorous PA (Farias Júnior et al., 2012). We identified whether students met or did not meet the World Health Organization's PA guidelines (420 min per week) at baseline (World Health Organization (WHO), 2010). Height and body weight were measured following international standardization (Lohman et al., 1988). The BMI (weight $(\mathrm{kg}) /$ height (Hallal et al., 2012) $\left(\mathrm{m}^{2}\right)$ ) was calculated and classified according to the age- and gender-specific cutoff points of the World Health Organization at normal weight and overweight (obesity included) (Md et al., 2007). All variables showed acceptable test-retest (two weeks apart) reliability (Barbosa Filho et al., 2015).

The Fortaleça sua Saúde program took place during the second semester of 2014, over approximately four months. The questionnaire was administered by evaluators to students in the classroom. Evaluators were not blinded to which schools were in the intervention and control treatments. Data were computed by scanning using the SPHYNX® software (Sphynx Software Solutions Inc., Washington, USA), with correction for error and/or inconsistencies. The intervention implementation was described previously (Barbosa Filho et al., 2016a).

\subsection{Data analyses}

The final sample of 1085 students has a statistical power to identify an effect size equal to or higher than 0.08 (e.g., intervention vs. control mean differences of 0.26 points on the PA facilities in school scale) in scores in the adjusted comparisons' group vs. time, considering a conservative intermeasured correlation of 0.1 (De Bock et al., 2013). In moderator analyses, categories with low sample size (overweight with 274 students, or higher SES with 277 students), the sample size power was sufficient to find effect sizes equal to or higher than 0.13 (e.g., mean differences of 0.41 points on the PA facilities in schools scale). All analyses were performed using the software GPower 3.1 (http://www.gpower.hhu.de/), considering $\beta=0.20$ and $\alpha=0.05$ (two-tailed tests).

We used a combination of visual inspection and assessment skewness and kurtosis (high when \pm 2 ) in order to assess the distribution of continuous data (George and Mallery, 2003). The data showed an asymmetric distribution and were log-transformed during the inferential analyses. Mean at baseline (standard deviation) or mean differences (confidence interval of 95\% [95\% CI]) between baseline and follow-up or between control and intervention groups were used to describe continuous variables. We used prevalence for categorical data at baseline.

We tested differences between control vs. intervention students at baseline using independent $t$-test and chi-square test for continuous and categorical variables, respectively. Generalized linear models were used to identify the intragroup (follow-up vs. baseline) and intergroups (group vs. follow-up) differences, with adjustment for confounders (i.e., clustering by school and variables at baseline). We tested the interaction between intervention effect and gender, age group, SES, BMI status, and PA level. When a statistically significant interaction was found $(P<0.10)$, we performed the analyses according to moderator categories (George and Mallery, 2003; Lubans et al., 2012). There was variance homogeneity between categories during moderator analyses. All analyses were performed considering students with pre- and postintervention data $(n=1085)$. We considered the level of significance of $5 \%$ for two-tailed tests, and we used the statistical software SPSS 23.0® (SPSS IBM Inc., Chicago, USA).

\section{Results}

The final sample ( $n=1085,51.5 \%$ of boys) included students who were 11 to 18 years old. Most of the included students were aged 11 to 13 years (52.9\%), normal weight (74.7\%), lower SES (73.9\%), and not meeting PA guidelines (58.2\%). Differences at baseline between control and intervention students were found for support of school's teachers, safety in neighborhood, PA facilities in neighborhood, and PA facilities in school $(P<0.05$, Table 1$)$.

After adjustment for confounders, we found a significant and positive intervention effect for attitude, support of friends, support of school's teachers, and PA facilities in school $(P<0.05)$, with effect sizes of $0.29,0.24,0.34$, and 0.29 , respectively. Age group was a significant moderator of the intervention effect for support of friends $(P=$ $0.04)$, support of parents $(P<0.01)$, support of school's teachers $(P=$ $0.03)$, and PA facilities in school $(P=0.01)$. SES was a moderator of the intervention effect for support of friends $(P=0.02)$ and $P A$ facilities in school $(P=0.02)$. BMI status was a moderator for support of friends $(P=0.04)$ (Table 2).

During the analyses according to moderator groups (Fig. 1 and Supplementary Material B), we found a negative intervention effect on support of parents among older students $(P<0.01)$, but not among younger students $(P=0.94)$. Inversely, there was a positive intervention effect on support of friends among older students $(P=0.01)$, but not among younger students $(P=0.06)$. There was a positive intervention effect on support of school's teachers $(P<0.01)$ and PA facilities in school $(P<0.01)$ for younger students, but not for older students ( $P$-values of 0.17 and 0.42 , respectively). In SES, there was a positive intervention effect on scores of support of friends $(P<0.01)$ and PA facilities in school $(P<0.01)$ for students from lower SES, but not for students from higher SES ( $P$-values of 0.34 and 0.79 , respectively). Finally, there was a significant and positive intervention effect on support of friends among normal weight students $(P<0.01)$, but not for overweight students $(P=$ $0.08)$.

\section{Discussion}

This study evaluated the effect of a multicomponent school-based intervention on potential PA determinants and whether gender, age, SES, nutritional status, and PA level at baseline were moderators of the intervention effect among Brazilian students. Our results confirmed that the intervention can improve some intrapersonal (attitude), interpersonal (social support of friends and school's teachers) and perceived environment (PA facilities in school) PA variables. However, some changes occurred differently according to age, SES and BMI status subgroups.

The intervention effect on attitude for PA practice was an important finding of this study. This potential PA determinant represents an individual assessment related to overall satisfaction on regular PA practice, considering both positive/negative and instrumental/emotional aspects that are related to PA practice (Brown et al., 2009). Previous systematic reviews have indicated that there is little or inconsistent evidence of the effect of interventions on attitude for PA (Demetriou and Höner, 2012; Perry et al., 2012; Brown et al., 2013; Salmon et al., 2009). A positive change on attitude for PA can be explained by the development of knowledge and interest in PA during strategies (e.g., lessons on general and PE classes, free-time games in school), which favors the positive perception of this intrapersonal PA determinant.

Social- (support of friends) and school-related (support of school's teachers and PA facilities in school) PA determinants also showed positive changes after the intervention, which were exciting results because the effect of interventions on these determinants is unclear (Demetriou and Höner, 2012; Perry et al., 2012; Salmon et al., 2009). Improving the perception of social support and the school environment for PA practice is important because these determinants can contribute to the adoption and maintenance of PA behavior among students (Eather et al., 2013; Yildirim et al., 2014). Our findings reinforce the importance of strategies in the school context that improve psychological aspects related to an active and healthy lifestyle and school involvement.

Age was a moderator, which implies changes in the direction and strength/significance of the intervention effect on potential PA 
Table 1

Students' characteristics at baseline among intervention and control students of the Fortaleça sua Saúde program study

\begin{tabular}{|c|c|c|c|c|}
\hline Characteristics at baseline $^{a}$ & Total $(n=1085)$ & $\begin{array}{l}\text { Intervention } \\
(n=548)\end{array}$ & $\begin{array}{l}\text { Control } \\
(n=537)\end{array}$ & $P$-value ${ }^{b}$ \\
\hline \multicolumn{5}{|l|}{ Categorical variables, $n(\%)$} \\
\hline Gender & & & & 0.84 \\
\hline Boys & $51.5(559)$ & $51.8(284)$ & $51.2(275)$ & \\
\hline Girls & $48.5(526)$ & $48.2(264)$ & $48.8(262)$ & \\
\hline Age groups (years) & & & & 0.39 \\
\hline $11-13$ & $52.9(574)$ & $54.2(297)$ & $51.6(277)$ & \\
\hline $14-18$ & $47.1(511)$ & $45.8(251)$ & $48.4(260)$ & \\
\hline SES & & & & 0.34 \\
\hline A + B (higher SES) & $25.5(277)$ & $27.5(150)$ & $23.8(127)$ & \\
\hline$C+D+E$ (lower SES) & $73.9(802)$ & $72.5(395)$ & $76.2(407)$ & \\
\hline BMI status & & & & 0.09 \\
\hline Normal weight & $74.7(811)$ & $71.1(381)$ & $77.4(406)$ & \\
\hline Overweight (obesity included) & $25.3(274)$ & $28.3(155)$ & $22.2(119)$ & \\
\hline \multicolumn{5}{|l|}{ PA level } \\
\hline Did not meet PA guidelines ( $<420$ min./wk. MVPA) & $58.2(632)$ & $60.0(329)$ & $56.4(303)$ & \\
\hline Met PA guidelines ( $\geq 420 \mathrm{~min} . / \mathrm{wk}$. MVPA) & $41.8(453)$ & $40.0(219)$ & $43.6(234)$ & 0.23 \\
\hline \multicolumn{5}{|l|}{ Continuous variables (mean $\pm \mathrm{SD}$ ) } \\
\hline \multicolumn{5}{|l|}{ Intrapersonal PA determinants } \\
\hline Attitude & $15.93(2.50)$ & $15.95(2.40)$ & $15.92(2.60)$ & 0.84 \\
\hline Self-efficacy & $20.76(3.51)$ & $20.74(3.53)$ & $20.79(3.50)$ & 0.85 \\
\hline \multicolumn{5}{|l|}{ Interpersonal PA determinants } \\
\hline Support of friends & $11.44(4.61)$ & $11.34(4.40)$ & $11.53(4.81)$ & 0.69 \\
\hline Support of parents & $10.99(4.25)$ & $11.17(4.33)$ & $10.80(4.16)$ & 0.19 \\
\hline Support of school's teachers & $10.71(4.01)$ & $10.41(3.95)$ & $11.03(4.06)$ & 0.01 \\
\hline \multicolumn{5}{|l|}{ Perceived PA environment determinants } \\
\hline Safety in neighborhood & $12.22(2.79)$ & $12.59(2.58)$ & $11.84(2.93)$ & $<0.01$ \\
\hline PA facilities in neighborhood & $12.29(2.85)$ & $12.61(2.88)$ & $11.94(2.79)$ & $<0.01$ \\
\hline PA facilities in school & $7.07(1.81)$ & $7.36(1.77)$ & $6.77(1.80)$ & $<0.01$ \\
\hline
\end{tabular}

Note: BMI: body mass index; Min./wk.: minutes per week; MVPA: moderate to vigorous physical activity; PA: physical activity; SES: socioeconomic status; SD: standard deviation.

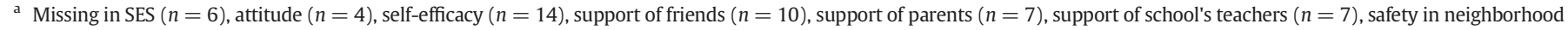
$(n=8)$, PA facilities in neighborhood $(n=41)$, and PA facilities in school $(n=1)$.

b $P$-value estimated using the Chi-square test for categorical variables and independent $t$-test for continuous variables, and continuous variables were log-transformed during data analyses.

determinants (see Fig. 1). Little evidence exists indicating that age is a moderator of the intervention effect on PA behavior in young people, (Yildirim et al., 2011) corroborating the Fortaleça sua Saúde program data (Barbosa Filho et al., 2016a). In this intervention, qualitative reports of teachers and school coordinators highlighted that some strategies, such as raising health issues in class and the use of active games

Table 2

Effect and moderators of the Fortaleça sua Saúde program on potential physical activity determinants among Brazilian students.

\begin{tabular}{|c|c|c|c|c|c|c|c|c|c|c|c|c|c|}
\hline \multirow[t]{2}{*}{ Potential PA determinants } & \multirow[t]{2}{*}{$\begin{array}{l}\text { Score } \\
\text { range }\end{array}$} & \multicolumn{4}{|c|}{ Difference follow-up vs. baseline ${ }^{a}$} & \multicolumn{3}{|c|}{$\begin{array}{l}\text { Difference intervention vs. } \\
\text { control }^{\mathrm{a}}\end{array}$} & \multicolumn{5}{|c|}{$\begin{array}{l}\text { Moderator vs. intervention effect } \\
(P \text {-value })^{\mathrm{b}}\end{array}$} \\
\hline & & $\begin{array}{l}\text { Intervention } \\
(n=548)\end{array}$ & $P$ & $\begin{array}{l}\text { Control } \\
(n=537)\end{array}$ & $P$ & $\begin{array}{l}\text { Mean difference } \\
(95 \% \mathrm{CI})\end{array}$ & $\begin{array}{l}\text { Effect } \\
\text { size }\end{array}$ & $P$ & Gender & $\begin{array}{l}\text { Age } \\
\text { group }\end{array}$ & SES & $\begin{array}{l}\text { BMI } \\
\text { status }\end{array}$ & PAL \\
\hline \multicolumn{14}{|l|}{ Intrapersonal determinants } \\
\hline Attitude & $5-20$ & $0.55(0.21 ; 0.88)$ & $<\mathbf{0 . 0 1}$ & $\begin{array}{l}-0.62(-0.97 \\
-0.28)\end{array}$ & $<\mathbf{0 . 0 1}$ & $\begin{array}{l}1.17(0.55 ; \\
1.79)\end{array}$ & 0.29 & $<0.01$ & 0.27 & 0.99 & 0.41 & 0.99 & 0.86 \\
\hline Self-efficacy & $8-32$ & $\begin{array}{l}-0.18(-0.72 \\
0.36)\end{array}$ & 0.09 & $\begin{array}{l}-0.49(-1.06 \\
0.07)\end{array}$ & 0.51 & $\begin{array}{l}0.31(-0.69 \\
1.32)\end{array}$ & 0.05 & 0.54 & 0.53 & 0.67 & 0.12 & 0.53 & 0.26 \\
\hline \multicolumn{14}{|l|}{ Interpersonal determinants } \\
\hline Support of friends & $5-20$ & $0.76(0.23 ; 1.29)$ & $<\mathbf{0 . 0 1}$ & $\begin{array}{l}-0.78(-1.33 ; \\
-0.23)\end{array}$ & $<\mathbf{0 . 0 1}$ & $\begin{array}{l}1.54(0.56 ; \\
2.52)\end{array}$ & 0.24 & 0.02 & 0.13 & 0.04 & 0.02 & 0.04 & 0.59 \\
\hline Support of parents & $6-24$ & $\begin{array}{l}-0.65(-1.13 \\
-0.16)\end{array}$ & $<0.01$ & $\begin{array}{l}0.20(-0.29 \\
0.68)\end{array}$ & 0.43 & $\begin{array}{l}-0.84(-1.73 \\
0.04)\end{array}$ & -0.15 & 0.08 & 0.47 & $<0.01$ & 0.22 & 0.18 & 0.14 \\
\hline $\begin{array}{l}\text { Support of school's } \\
\text { teachers }\end{array}$ & $5-20$ & $1.30(0.76 ; 1.83)$ & $<\mathbf{0 . 0 1}$ & $\begin{array}{l}-0.84(-1.40 \\
-0.29)\end{array}$ & $<\mathbf{0 . 0 1}$ & $\begin{array}{l}2.14(1.16 ; \\
3.13)\end{array}$ & 0.34 & $<\mathbf{0 . 0 1}$ & 0.15 & 0.03 & 0.66 & 0.41 & 0.45 \\
\hline \multicolumn{14}{|l|}{$\begin{array}{l}\text { Perceived environment } \\
\text { determinants }\end{array}$} \\
\hline Safety in neighborhood & $5-20$ & $\begin{array}{l}-0.17(-0.53 \\
0.19)\end{array}$ & 0.36 & $\begin{array}{l}-0.29(-0.66 \\
0.08)\end{array}$ & 0.13 & $\begin{array}{l}0.12(-0.55 \\
0.79)\end{array}$ & 0.03 & 0.72 & 0.17 & 0.32 & 0.26 & 0.45 & 0.66 \\
\hline $\begin{array}{l}\text { PA facilities in } \\
\text { neighborhood }\end{array}$ & $5-20$ & $\begin{array}{l}-0.16(-0.59 \\
0.27)\end{array}$ & 0.48 & $\begin{array}{l}-0.21(-0.66 \\
0.24)\end{array}$ & 0.36 & $\begin{array}{l}0.05(-0.75 \\
0.85)\end{array}$ & 0.01 & 0.90 & 0.62 & 0.44 & 0.59 & 0.60 & 0.86 \\
\hline PA facilities in school & $3-12$ & $\begin{array}{l}0.25(-0.02 \\
0.52)\end{array}$ & 0.06 & $\begin{array}{l}-0.68(-0.96 \\
-0.41)\end{array}$ & $<\mathbf{0 . 0 1}$ & $\begin{array}{l}0.93(0.44 \\
1.43)\end{array}$ & 0.29 & $<\mathbf{0 . 0 1}$ & 0.89 & 0.01 & 0.02 & 0.71 & 0.26 \\
\hline
\end{tabular}

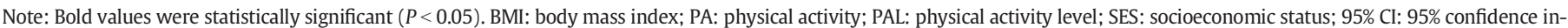

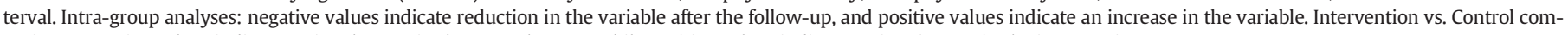
parison: negative values indicate major changes in the control group, while positive values indicate major changes in the intervention group.

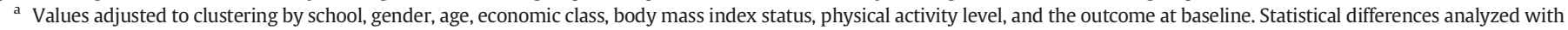
generalized linear models, considering the transformed data for inferential analyses.

b The analyses of moderators of the intervention effect was adjusted for all other confounders included in the main analysis. 

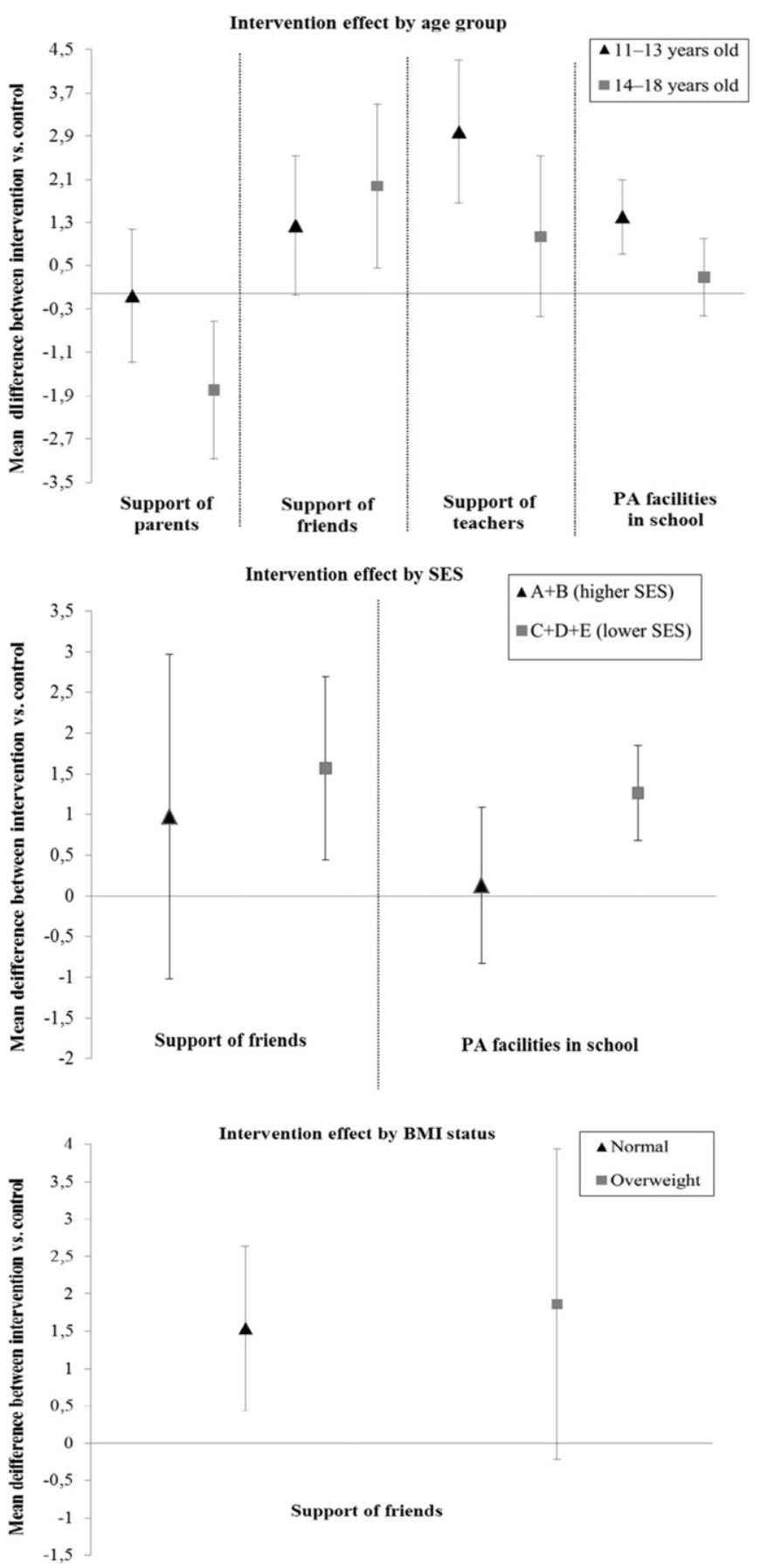

Fig. 1. Mean difference (95\% confidence interval) between intervention vs. control group of potential physical activity determinants according to moderator categories. Note: BMI: body mass index; PA: physical activity; SES: socioeconomic status. Mean difference between intervention vs. Control: negative values indicate major changes in the control group, while positive values indicate major changes in the intervention group. Values adjusted to clustering by school, gender, age, economic class, body mass index status, physical activity level, and the outcome at baseline. Statistical differences analyzed with Generalized Linear Models, considering the transformed data for inferential analyses.

during free-time in school, secured greater interest and participation from younger students (Barbosa Filho et al., 2016a). This may partly explain these findings.

However, older students improved their support of friends and, conversely, support of parents for PA reduced after intervention in this subgroup. Different interventions failed to change social support for PA practice among students, (Bergh et al., 2012; Lubans et al., 2012) and no robust reasons can justify our findings on the moderating role of age. One hypothesis is that, during adolescence and searching for more autonomy from their parents, students tend to start a gradual process of increasing the importance of friends' influence on their behaviors and beliefs (Cook et al., 2014). Our baseline data support this hypothesis because there are positive correlations between age and scores of support of friends $(r=0.073 ; P=0.02)$ and negative correlations with scores of support from parents $(r=-0.071 ; P=0.02$, data not shown). In practical terms, age seems to be one of the main aspects to be considered in defining strategies for interventions focused on PA behavior and determinants in the school setting. Our findings suggest, for example, that an emphasis on the support of friends can be focused on PA-promoting policies among older students, while the focus in the school context may favor younger students.

The intervention effect on support of friends and PA facilities in school occurred in students from lower SES, which is an innovating result of this study (Yildirim et al., 2011). Students from lower SES have limited opportunities to access structured PA or leisure-time PA, (Barbosa Filho et al., 2016a) and the school probably becomes the main context for psychosocial stimulation for PA practice. This intervention was conducted in schools from low HDI areas, in which students tend to be more exposed to violence, and have more difficulty accessing education and health facilities. This aspect reinforces these findings and indicates that intervention strategies in the school setting should be stimulated in order to reduce social disparities in PA practice and potential PA determinants.

BMI was a moderator of the intervention effect on support of friends for PA. Conversely, Bergh et al (Bergh et al., 2012). found that an intervention can lead to negative effects on potential PA determinants, such as self-efficacy and enjoyment, among 11-year-old overweight students. Importantly, our study found similar mean differences in normal weight and overweight students ( 0.12 and 0.10 , respectively), but the sample of overweight students $(n=274)$ had insufficient statistical power to find significance (power of 0.68 , considering alpha of $5 \%$ ). Therefore, future publications with more extensive samples of overweight and obese students are needed to confirm the findings.

Gender and PA level were not moderators of the intervention effect on PA determinants. Although these variables were associated with potential PA determinants in young people, (Grydeland et al., 2013) evidence on the moderating effect of these variables is scarce (Yildirim et al., 2011; Grydeland et al., 2013; Taymoori et al., 2008). Students from different genders and PA levels can be interested in different ways in multicomponent interventions (e.g., dancing games attract more girls, while competitive sport events attract more active students). However, our results indicate that this multicomponent intervention can be implemented in a real context and similarly affect PA determinants independently of gender and PA level of students.

This was one of the first intervention studies focused on the question "for whom was it effective?" for potential PA determinants (Bergh et al., 2012). This study evaluated several modifiable PA determinants, which helps us to understand how multicomponent strategies can change young people's perception of intrapersonal, interpersonal and environmental PA determinants (Demetriou and Höner, 2012; Perry et al., 2012; Brown et al., 2013). Finally, this was one of the first schoolbased interventions to be performed in low HDI areas from a low- and middle-income country.

The study's limitations included some differences at baseline between the intervention and control groups, and the cluster randomized-controlled trial may explain these findings. However, we used the adjustment for confounding variables aiming to overcome such limitations. Another limitation was that some scales had substantial reliability (intraclass correlation coefficients ranging from 0.60 to 0.70), (Barbosa Filho et al., 2016b) which can impact the real effect size of this intervention. Low psychometric properties have been common in scales of PA determinants among adolescents (Brown et al., 2009). Finally, the four-month intervention may be insufficient to change some PA determinants. This study will stimulate long-term 
studies (including follow-up measures after intervention) focused on these potential PA determinants.

\section{Conclusion}

The intervention had a positive effect on promoting some potential PA determinants among students. However, the intervention was not effective for all subjects in support of friends for PA (only in older students, who had lower SES and were of normal weight), support of the school's teachers for PA (only in younger students), PA facilities in school (only in younger students and who had lower SES), and the support of parents for PA (negative intervention effect in older students only). These findings suggest that interventions can change PA determinants in specific population subgroups, which should be considered in defining the PA-promotion strategies in students in the school context.

\section{Transparency document}

The Transparency document associated with this article can be found, in online version.

\section{Authors' contributions}

VCBF participated in all stages of the study, including design, implementation and supervision of the program, data analyses, and he drafted the first version of the manuscript. KSS, JM, NFCV, FAG, and ASL participated in the design, planning and supervision of the program, data interpretation and draft of the manuscript. All authors approved the final version of the manuscript.

\section{Acknowledgments}

There was no financial funding to perform this study. Individual grants for VCBF (N. 10737/2014-6) from the Coordenação de Aperfeiçoamento de Pessoal de Nível Superior (CAPES), and ASL (N. 303012/2013-7) from the Conselho Nacional de Ciência e Tecnologia (CNPQ). The funding agencies had no participation in the interpretation, analysis, writing and approval of this manuscript.

We thank the Municipal Education Department for technical support and authorization to the study execution. We thank all members of the school community (managers, teachers, parents and students) who were involved in this study. "Fortaleça sua Saúde" Working Group:

Management Team: Adair S. Lopes, Antônio B. Lima, Evanice A. Souza, Fabiane A. Gubert, Kelly S. Silva, Neiva F.C. Vieira, Nicolino Trompieri Filho, Thábyta S. Araújo e Valter C. Barbosa Filho.

Executing Team: Alana G. Caetano, Alexsandra S. Bandeira, Antônia E. Sousa, Dayane O. Falcão, Deuziane T.F. Brito, Iraneide E. Lopes, Jéssica S. Martins, José M. Alves, Nairton S. Pinheiro, Raguel T. Pinto, Sarah C. Paulino, Soraya A. Sá, Tiago P. Nascimento e Valberson S. Pereira.

\section{Appendix A. Supplementary data}

Supplementary data to this article can be found online at http://dx. doi.org/10.1016/j.ypmed.2017.01.007.

\section{References}

Associação Brasileira das Empresas de Pesquisa, 2013. Critério de classificação econômica Brasil ABEP, São Paulo (Available at: http://www abep.org/. Accessed Feb 02, 2014).

Barbosa Filho, V.C., Lopes, A.S., Lima, A.B., et al., 2015. Rationale and methods of a clusterrandomized controlled trial to promote active and healthy lifestyles among Brazilian students: the "Fortaleça sua Saúde" program. BMC Public Health 15, 1212.

Barbosa Filho, V.C., Silva, K.S., Mota, J., et al., 2016a. A physical activity intervention for Brazilian students from low human development index areas: a clusterrandomized controlled trial. J. Phys. Act. Health 13 (11):1174-1182. http://dx.doi org/10.1123/jpah.2016-0113.

Barbosa Filho, V.C., Rech, C.R., Mota, J., et al., 2016b. Validity and reliability of scales on intrapersonal, interpersonal and environmental factors associated with physical activity in secondary students. Rev. Bras. Cineantropom. Desempenho Hum. 18 (2): 207-231. http://dx.doi.org/10.5007/1980-0037.2015v18n2p207.

Bergh, I.H., Bjelland, M., Grydeland, M., et al., 2012. Mid-way and post-intervention effects on potential determinants of physical activity and sedentary behavior, results of the HEIA study-a multi-component school-based randomized trial. Int. J. Behav. Nutr. Phys. Act. 9:63. http://dx.doi.org/10.1186/1479-5868-9-63.

Brown, H., Hume, C., Paw, M.C., 2009. Validity and reliability of instruments to assess potential mediators of children's physical activity: a systematic review. J. Sci. Med. Sport 12 (5):539-548. http://dx.doi.org/10.1016/j.jsams.2009.01.002.

Brown, H., Hume, C., Pearson, N., Salmon, J., 2013. A systematic review of intervention effects on potential mediators of children's physical activity. BMC Public Health 13:165. http://dx.doi.org/10.1186/1471-2458-13-165.

Cook, T.L., De Bourdeaudhuij, I., Maes, L., et al., 2014. Moderators of the effectiveness of a web-based tailored intervention promoting physical activity in adolescents: the HELENA activ-o-meter. J. Sch. Health 84 (4):256-266. http://dx.doi.org/10.1111/ josh.12140.

De Bock, F., Genser, B., Raat, H., et al., 2013. A participatory physical activity intervention in preschools: a cluster randomized controlled trial. Am. J. Prev. Med. 45 (1), 64-74.

Demetriou, Y., Höner, O., 2012. Physical activity interventions in the school setting: a systematic review. Psychol. Sport Exerc. 13 (2):186-196. http://dx.doi.org/10.1016/j. psychsport.2011.11.006.

Eather, N., Morgan, P.J., Lubans, D.R., 2013. Social support from teachers mediates physical activity behavior change in children participating in the fit-4-fun intervention. Int. J. Behav. Nutr. Phys. Act. 10:68. http://dx.doi.org/10.1186/1479-5868-10-68.

Farias Júnior, J.C., Lopes, A.S., Mota, J., et al., 2012. Validity and reproducibility of a physical activity questionnaire for adolescents: adapting the self-administered physical activity checklist. Rev. Bras. Epidemiol. 15 (1), 198-210.

Ferreira, I., Van Der Horst, K., Wendel-Vos, W., et al., 2007. Environmental correlates of physical activity in youth-a review and update. Obes. Rev. 8 (2):129-154. http:// dx.doi.org/10.1111/j.1467-789X.2006.00264.X.

George, D., Mallery, P., 2003. SPSS for Windows Step by Step: A Simple Guide and Reference. (Available at: http://wps.ablongman.com/wps/media/objects/385/394732/ george4answers.pdf. Accessed 13 May 2015).

Grydeland, M., Bergh, I.H., Bjelland, M., et al., 2013. Intervention effects on physical activity: the HEIA study-a cluster randomized controlled trial. Int. J. Behav. Nutr. Phys. Act. 10:17. http://dx.doi.org/10.1186/1479-5868-10-17.

Gubbels, J.S., Van Kann, D.H., de Vries, N.K., et al., 2014. The next step in health behavior research: the need for ecological moderation analyses-an application to diet and physical activity at childcare. Int. J. Behav. Nutr. Phys. Act. 11:52. http://dx.doi.org/ 10.1186/1479-5868-11-52.

Hallal, P.C., Andersen, L.B., Bull, F.C., et al., 2012. Global physical activity levels: surveillance progress, pitfalls, and prospects. Lancet 380 (9838):247-257. http://dx.doi. org/10.1016/S0140-6736(12)60646-1.

Instituto Brasileiro de Geografia e Estatística, 2010. IBGE: Censo. (Available at: http:// cidades.ibge.gov.br/xtras/perfil.php?codmun=230440. Accessed 5 September 2014).

Langford, R., Bonell, C.P., Jones, H.E., et al., 2014. The WHO health promoting school framework for improving the health and well-being of students and their academic achievement. Cochrane Database Syst. Rev. 4, CD008958.

Lohman, T.G., Roche, A.F., Martorell, R., 1988. Anthropometric Standardization Reference Manual. Human Kinetics Books, Champaign.

Lubans, D.R., Morgan, P.J., Callister, R., 2012. Potential moderators and mediators of intervention effects in an obesity prevention program for adolescent boys from disadvantaged schools. J. Sci. Med. Sport 15 (6):519-525. http://dx.doi.org/10.1016/j.jsams. 2012.03.011.

Md, O., Onyango, A.W., Borghi, E., et al., 2007. Development of a WHO growth reference for school-aged children and adolescents. Bull. World Health Organ. 85 (9), 660-667.

Perry, C.K., Garside, H., Morones, S., Hayman, L.L., 2012. Physical activity interventions for adolescents: an ecological perspective. J. Prim. Prev. 33 (2-3):111-135. http://dx.doi. org/10.1007/s10935-012-0270-3.

Sallis, J.F., Owen, N., Fisher, E.B., 2008. Ecological models of health behavior. In: Glanz, K., Rimer, B.K., Viswanath, V. (Eds.), Health Behavior and Health Education: Theory, Research, and Practice, pp. 465-486.

Salmon, J., Brown, H., Hume, C., 2009. Effects of strategies to promote children's physical activity on potential mediators. Int. J. Obes. 33 (Suppl.1):S66-S73. http://dx.doi.org/ 10.1038/ijo.2009.21.

Taymoori, P., Niknami, S., Berry, T., et al., 2008. A school-based randomized controlled trial to improve physical activity among Iranian high school girls. Int. J. Behav. Nutr. Phys. Act. 5:18. http://dx.doi.org/10.1186/1479-5868-5-18.

World Health Organization (WHO), 2010. Global Recommendations on Physical Activity for Health. WHO, Geneva (Avaliable at: http://apps.who.int/iris/bitstream/10665/ 44399/1/9789241599979 eng.pdf. Accessed November 23, 2013).

World Health Organization (WHO), 2013. Global Action Plan for the Prevention and Control of Noncommunicable Diseases 2013-2020. WHO, Geneva (Available at: http:// apps.who.int/iris/bitstream/10665/94384/1/9789241506236_eng.pdf. Accessed July $10,2014)$.

Yildirim, M., Stralen, M.M., Chinapaw, M.J., et al., 2011. For whom and under what circumstances do school-based energy balance behavior interventions work? Systematic review on moderators. Int. J. Pediatr. Obes. 6 (2):46-57. http://dx.doi.org/10.3109/ 17477166.2011 .566440$.

Yildirim, M., Arundell, L., Cerin, E., et al., 2014. What helps children to move more at school recess and lunchtime? Mid-intervention results from transform-us! Clusterrandomised controlled trial. Br. J. Sports Med. 48 (3):271-277. http://dx.doi.org/10. 1136/bjsports-2013-092466. 